\title{
Parental Hesitation as a Factor in Delayed Childhood Immunization
}

Karlen E. (Beth) Luthy

Brigham Young University - Provo, beth_luthy@byu.edu

Renea L. Beckstrand

Brigham Young University - Provo

Neil E. Peterson

Follow this and additional works at: https://scholarsarchive.byu.edu/facpub

Part of the Other Nursing Commons, Pediatric Nursing Commons, and the Public Health and Community Nursing Commons

\section{Original Publication Citation}

Luthy, K. E., Beckstrand, R. L., \& Peterson, N. E.* (2009). Parental hesitation as a factor in delayed childhood immunization. Journal of Pediatric Health Care, 23(6), 388-393.

\section{BYU ScholarsArchive Citation}

Luthy, Karlen E. (Beth); Beckstrand, Renea L.; and Peterson, Neil E., "Parental Hesitation as a Factor in Delayed Childhood Immunization" (2008). Faculty Publications. 5227.

https://scholarsarchive.byu.edu/facpub/5227

This Peer-Reviewed Article is brought to you for free and open access by BYU ScholarsArchive. It has been accepted for inclusion in Faculty Publications by an authorized administrator of BYU ScholarsArchive. For more information, please contact ellen_amatangelo@byu.edu. 


\section{Parental Hesitation}

as a Factor in

Delayed Childhood Immunization

\author{
Karlen E. Luthy, APRN, FNP, \\ Renea L. Beckstrand, PhD, RN, CCRN, \\ \& Neil E. Peterson, RN, BS
}

\begin{abstract}
Introduction: One reason for lower immunization rates is that some parents hesitate to have their children immunized. A hesitancy questionnaire was developed to identify reasons parents hesitate in having their children immunized.

Methods: The hesitancy questionnaire was distributed from local pediatric and family practice offices and from the area's county health department. To be eligible, participants needed to be present in the clinic with a child needing a minimum of one immunization that was at least 6 months overdue.

Results: When questioned why their child was overdue for immunizations, the most common response was that participants were confused about the immunization schedule and not sure when to return. Of the participants who reported having concerns regarding immunizations, the child's pain/crying/anxiety was the most commonly occurring answer. When asked where they receive the majority of childhood immunization information, participants frequently identified their health care provider as the main source of information.

Discussion: Health care providers may be missing opportunities to educate hesitant parents about immunizations. Parents may not have ample opportunities to discuss their immunization concerns in detail with their health care provider during regularly scheduled clinic visits. It is important for health care providers to suggest ways
\end{abstract}

Karlen E. Luthy, Assistant Professor, College of Nursing, Brigham Young University, Provo, UT.

Renea L. Beckstrand, Associate Professor, Brigham Young University, Provo, UT.

Neil E. Peterson, Registered Nurse, Cleveland Clinic, Cleveland, $\mathrm{OH}$.

Correspondence: Karlen E. Luthy, APRN, FNP-c, College of Nursing, Brigham Young University, 355 SWKT, Provo, UT 84602; e-mail: Beth_luthy@byu.edu.

Statement of Conflict of Interest: See page 393.

0891-5245/\$36.00

Copyright $(\mathcal{2} 2009$ by the National Association of Pediatric Nurse Practitioners.

doi:10.1016/j.pedhc.2008.09.006 parents can cope with their child's pain/crying/anxiety when receiving immunizations. J Pediatr Health Care. (2009) 23, 388-393.

Key words: Immunizations, immunization hesitancy, parental hesitancy, immunization education.

Despite worldwide progress toward controlling the spread of communicable disease through the use of vaccines, some communities continually struggle with maintaining immunization compliance among community members (Smith, Chu, \& Barker, 2004). One such community in Utah reported that only $71 \%$ of the children living in the county were adequately immunized, compared with the national average of 81\% (Utah Department of Health, 2006). The lower county immunization rates may be related to the alarming state-wide trend of an increased number of parents who hesitate in having their children receive immunizations in a timely manner (Green \& Lee, 2006).

Nationally, having more than three children in the family is a strong determinate of immunization noncompliance (Bundt \& $\mathrm{Hu}$, 2002). Utah residents have a difficult time in maintaining compliance with immunizations, most likely because they have the highest average number of people per family, 3.57, compared with the national average of 2.59 (Green \& Lee, 2006; Simmons \& O'Neill, 2001; United States Census Bureau, 2000a, 2000b). Utah residents also may have a difficult time in maintaining compliance with immunizations because they have the highest birth rate in the country (Green \& Lee; Simmons \& O'Neill).

Nationwide, two very distinct populations are responsible for the decline in adequately immunized children: parents who 
exempt themselves from immunizing their children and parents who hesitate or delay in having their children immunized (Green \& Lee, 2006). An increasing number of parents hesitate to have their children vaccinated for various reasons such as vaccine safety concerns and problems with access to health care (Gust et al., 2004). Many of these children who are not vaccinated on time, at appropriate intervals, fall between the ages of 0 to 2 years and are classified as under-immunized (Luman, McCauley, Stokley, Chu, \& Pickering, 2002). Under-immunization is a problem because it contributes to the overall reduction of community immunity to various vaccine-preventable illnesses, thus increasing the risk for a disease outbreak (Cochran, Smith, Reid, Morrow, \& Ramirez, 2003; Luman, Barker, McCauley, \& Drews-Botsch, 2005).

Ordinarily, parents of under-immunized children include young mothers who are not married, do not have a college degree, and have an annual income near the poverty level (Luman, Barker, Shaw, et al., 2005; Smith et al., 2004). To determine if the Utah community was similar to this national profile, a hesitancy questionnaire was developed and distributed to parents of underimmunized children. The questionnaire was placed in the local county health department and in local pediatric and family practice offices to assess parental perceptions regarding childhood immunization, ascertain demographic information about parents who hesitate, and identify potential barriers to adequate and timely vaccination. Accordingly, the purposes of this study were to identify the reasons why parents hesitate in having their children immunized and to describe other potential barriers to receiving vaccines.

\section{METHOD}

Prior to questionnaire development, multiple searches of elec- tronic bibliographic databases were examined to identify and collect studies related to childhood vaccines and vaccine hesitancy. Databases utilized in the search included MEDLINE, MEDLINEPlus, EBSCO, PubMed, MD Consult, CINAHL, Clinical Pharmacology, Web of Science, Biomedical Reference Collection-Basic, Health Source-Nursing/Academic Edition, Ovid, and the Cochrane Library Online. Additionally, current guidelines and recommendations for childhood immunizations were collected by conducting an Internet search from the Centers for Disease Control and Prevention, the National Association of Pediatric Nurse Practitioners, and the American Academy of Pediatrics Web sites.

The hesitancy questionnaire was developed to assess parental attitudes and beliefs among those who hesitate to have their children immunized. Questionnaire items were chosen based on commonly identified parental concerns and other perceived barriers to immunization as identified in the literature, such as access to immunizations and insurance coverage (Kim, Frimpong, Rivers, \& Kronenfeld, 2007). In addition, the questionnaire was reviewed by a local immunization coalition consisting of experts in public health, pediatrics, and state and local government agencies.

Following institutional review board approval, the hesitancy questionnaire was distributed from local pediatric and family practice offices and from the area's county health department among eligible parents to determine the parental concerns and perceived barriers that caused parents to hesitate in having their children immunized. Participants needed to be present in the clinic with a child requiring a minimum of one immunization that was at least 6 months overdue. The point of contact was either with nurses or medical assistants at local participating pediatric offices or the local health department. Parents fitting the inclusion criteria were offered a parental questionnaire with accompanying consent form.

If the parent wished to participate in the study, he or she read the consent and completed and returned the questionnaire. There was no incentive to participate, and participation in the study was purely voluntary. Participants were informed that they could skip any question that they chose not to answer. All parental questionnaires were collected from each of the sites by the principle investigator 6 weeks after the start date.

Responses were entered into an SPSS database (SPSS, Inc., Chicago, IL). The accuracy of the entered data was checked by two researchers. While one researcher read the marked responses from the returned questionnaire, the second researcher verified that the entered data were correct. When a discrepancy existed between the marked and printed responses, the primary investigator made the final decision about which number to enter. All 86 questionnaires were data checked in this manner. Frequencies and percentages were calculated for all items.

The single-page immunization questionnaire consisted of three questions regarding why the participant hesitated to immunize their child, what the participant's concerns were regarding immunizations, and where they received the majority of their information regarding immunizations. Each of these three questions had up to eight items or choices listed that could be checked, along with a last item listed with "other" and space to enter an open-ended written response. Participants were instructed to check all the items that applied.

The questionnaire also contained 11 demographic questions. Demographic data gathered included the sex, age, and race of the participant completing the questionnaire. In addition, participants 
were asked about their level of education, household income, and whether the household income was a single or dual income.

\section{RESULTS}

Of the 86 participants sampled, 71 reported their sex, with 70 (98.6\%) being female and 1 (1.4\%) being male. The participants ranged in age from 20 years to 45 years with an average age of 30 years (SD 6.3). Of the 69 respondents who reported their level of education, $47.8 \%$ had some college experience, while $30.4 \%$ of the sample reported graduating from college. There were $14.5 \%$ who stated that they had at least a high school education, and $7.2 \%$ stated they had only had some high school education. Household income was reported by 71 subjects. The choices for income range were less than $\$ 15,000$ to greater than $\$ 75,001$. Of the choices provided for participants, the average income was slightly below $\$ 45,000$. Sixty-eight subjects reported whether their household income was single or dual. Of those reporting a single or dual income household income, $88.2 \%$ had single family incomes while $11.8 \%$ reported having a dual family income.

Of the sample, 71 participants reported their race. Most of the participants who reported their race were White (70.4\%), with Hispanics being the next highest at $23.9 \%$. Additional reported races were Hawaiian or Pacific Islander (1.4\%) or those who subclassified as other (4.2\%). The number of children in a family ranged between one and eight children, with the mean at 3.14 (SD 1.6). The age of the child overdue for immunizations ranged from 6 months to 17 years, with the average age being $3 \frac{1}{2}$ years. When asked if they had received immunizations as a child, 79 out of 86 of the participants $(91.9 \%)$ stated they had received immunizations as a child. Of the 80 participants

TABLE 1. Most common reasons childhood immunizations are delayed

\begin{tabular}{lcc}
\multicolumn{1}{c}{ Selected parental response } & Frequency & Percent \\
\hline Confusing immunization schedule & 22 & 25.6 \\
Concerns about vaccine safety & 21 & 24.4 \\
Difficulty finding the time to immunize child & 20 & 23.3 \\
Wanting child to be older & 12 & 14.0 \\
Loss of immunization record & 9 & 10.5 \\
\hline
\end{tabular}

who reported on insurance coverage, $87.5 \%$ stated that their insurance program paid for the cost of the immunization. Seventy-four participants responded to whether they had received information about childhood immunizations at the previous clinic visit. Of the 74 who responded, $73 \%$ reported they had received childhood immunization information during the previous visit.

When questioned about why their child was overdue for immunizations, the 86 participants could choose from eight listed items and were encouraged to choose all items that applied. Participants selected a total of 108 responses. The most common response for why participants were late immunizing their child was that they were confused about the immunization schedule (25.6\%) and were not sure when they should return (Table 1). The participants also cited concern about the safety of vaccines $(24.4 \%)$ as a reason why they were late immunizing their children. Another $23.3 \%$ of participants reported they had difficulty finding time to update their child's immunizations. Some of the participants (14\%) stated they were late in having their child immunized because they wanted the child to be older before receiving their immunizations. A few participants reported other reasons for having the child immunized late, including the expensive cost of immunizations (10.5\%), having a sick child (9.3\%), loss of immunization record (5.8\%), transportation problems $(3.5 \%)$, or insurance problems $(3.5 \%)$
For the item regarding the participant having concerns about immunizing their child the day of the clinic visit, there were seven listed items from which to choose. Participants selected a total of 121 items. Of the participants who reported having concerns regarding immunizations, the most common response $(34.9 \%)$ was that they were worried about their child's pain/ crying/anxiety relating to the immunization (Table 2). Short-term adverse effects of the immunization, namely fever or pain at the injection site, were reported as a concern for $29.1 \%$ of participants. Concern regarding the overall safety of vaccines was reported by $24.4 \%$ of participants. Apprehension that immunizations overload a child's immune system was a concern for $20.9 \%$ of participants. The number of vaccines combined in one shot was a concern for $16.3 \%$ of participants. Additional immunization concerns included the number of shots the child received during the same clinic visit. In fact, $12.8 \%$ of participants listed the number of shots their child received at one clinic visit as a concern.

When questioned regarding the major source of immunization information, participants could choose from seven items. Participants provided a total of 101 selected items. The most commonly cited source of childhood immunization information (70.9\%) was the health care provider (Table 3). A family member was reported as a source of information for $12.8 \%$ of participants, while the local county health department was cited as a primary source of 
TABLE 2. Most common parental concerns regarding childhood immunizations

\begin{tabular}{lcc}
\multicolumn{1}{c}{ Selected parental response } & Frequency & Percent \\
\hline Child's pain/crying/anxiety & 30 & 34.9 \\
Short-term adverse effects & 25 & 29.1 \\
Overall safety of vaccines & 21 & 24.4 \\
Possibility of overloading child's immune system & 18 & 20.9 \\
Number of vaccines combined in one shot & 14 & 16.3 \\
\hline
\end{tabular}

\section{TABLE 3. Most common sources for childhood immunization information}

\begin{tabular}{lcc} 
Selected parental response & Frequency & Percent \\
\hline Health care provider & 61 & 70.9 \\
Family members & 11 & 12.8 \\
Local health department & 10 & 11.6 \\
Internet Web site & 8 & 9.3 \\
\hline
\end{tabular}

immunization information for $11.6 \%$ of participants. Internet resources were only identified as the major source of information for 9.3\% of participants, and of these participants, Autism Research Review International was the most frequently listed Internet Web site. Only 5.8\% of participants stated that their friends were their main source of immunization information. Other resources such as books or research articles were reported as the main source of immunization information for $5.8 \%$ of participants. The Centers for Disease Control and Prevention was listed as the major immunization information source for only $1.2 \%$ of participants.

\section{DISCUSSION}

When compared with the national profile of hesitant parents, the Utah study had similar findings. It was initially believed that because Utah has an above average number of children per family, coupled with the fact that having more than three children in the family is a strong determinate of noncompliance with childhood immunizations, the participants in the Utah study would have similar family characteristics. Indeed, the average number of children of the participants was 3.14, reinforcing the fact that nationally, families with more than three children have a difficult time immunizing their children in a timely manner.

There were, however, some differences between the national demographic profile of hesitant parents and hesitant parents in the Utah community. Nationally, under-vaccinated children are more likely to have a hesitant parent who is a young, Black mother. These mothers often have an education level of either high school or some college and usually report a household annual income below the poverty level (Smith et al., 2004). Differing from the national average, most hesitant parents in the Utah community were 30year-old White mothers. Most of the hesitant parents in the Utah community also reported a higher education level, with either some college or graduating from college (78.2\%). In addition, the reported annual household income among hesitant parents in Utah was approximately $\$ 45,000$ and was a single household income $88.2 \%$ of the time, suggesting that the majority of these mothers are different from the national demographic profile of hesitant parents.

When asked why the child was late in receiving his or her vaccina- tions, the most commonly occurring answer was that parents were confused about the immunization schedule (25.6\%) and were not sure when they should return to have their child receive the next set of immunizations. When considering that $73 \%$ of these parents also reported receiving immunization information at the previous clinic visit, perhaps the problem is not necessarily in communication between health care provider and parent but instead a problem of parents remembering the health care provider's counsel. Given that the remaining $27 \%$ of hesitant parents reported they had not received any information regarding childhood immunizations at the previous clinic visit indicates that health care providers may be missing opportunities to educate hesitant parents on when to return for the child's next set of immunizations.

When asked if they had concerns about having their child receive immunizations during the clinic visit, $24.4 \%$ of participants had concerns regarding vaccine safety. In this study, specific concerns regarding childhood immunizations included the number of shots the child might receive at one time and the possibility of overloading the child's immune system. Immunization concerns among hesitant parents identified in other studies include concern over vaccine ingredients and the worry that the child will develop a disease from the immunization itself (Niederhauser \& Markowitz, 2007; Shui, Weintraub, \& Gust, 2006). However, because most parents (70.9\%) also reported they receive the majority of immunization information from their health care provider, it is unclear as to why the parents continue to report immunization safety concerns. Perhaps the parents receive the majority of their immunization information from their health care provider but do not have ample opportunity to discuss these 
specific concerns in detail with their health care provider during clinic visits.

Additional parental responses regarding concerns of childhood immunizations included issues with the child's pain/crying/anxiety and the short-term adverse effects associated with receiving an immunization such as fever or pain at the injection site. Because these items were chosen frequently, the influence of a child's pain/crying/anxiety and concern of short-term adverse effects on a parent's willingness to immunize their children on time should not be underestimated. According to Cassidy et al. (2002), up to one fifth of children experience clinically significant pain when receiving an immunization. A high level of pain during a child's immunizations also is related to a high level of the child's anxiety, especially when returning for additional immunizations. Unfortunately, this high level of anxiety for the child may translate into a high level of anxiety for the parent, thus promoting parental procrastination of future immunizations (Schechter et al., 2007). In response, it is appropriate for the health care provider to specifically address these parental concerns and make recommendations on how to cope with a child's pain/crying/anxiety when receiving an immunization. In addition, it is appropriate to educate parents on the common adverse effects of vaccines and measures they can take to relieve the child's fever or pain at the injection site.

\section{CLINICAL IMPLICATIONS}

Originally it was assumed that the demographics of under-immunized children in the Utah community would be similar to national trends; however, key differences existed in socioeconomic status, level of education, and race. Consequently, nurse practitioners (NPs) should familiarize themselves with the demographic profile of their patients. Understanding the demographic profile of the target population may be especially helpful when creating interventions to increase immunization levels. Thus, it is important to identify population specifics in the local community before implementing interventions, because the demographics of parents who hesitate in immunizing their children in a local community may differ from those of the national community at large.

Confusion for parents regarding the immunization schedule is a common barrier to having an adequately immunized child nationwide (Kimmel, Burns, Wolfe, \& Zimmerman, 2007). To reduce parental confusion on when to return to the clinic for the child's next immunization, NPs could facilitate an immunization reminder program in their respective clinics where office staff could provide a postcard or telephone call to effectively remind parents to return for subsequent immunizations in a timely manner. In addition, NPs could briefly discuss the child's immunization status at each clinic visit, providing reminders on when the child is due for the next immunization in the series and encouraging parents to make the next clinic appointment for immunizations before leaving the clinic. Essentially, the parents need to be frequently reminded of when to return for their child's next immunization.

Most parents report receiving the majority of their immunization information from the health care provider, although they still report having immunization concerns. Perhaps these parents feel as though their immunization concerns are not being adequately addressed. As the primary point of contact, NPs have the ability to utilize clinic visits as an opportunity for encouraging dialogue regarding common immunization concerns. Recognizing that the ability to facilitate an immunization dia- logue with parents may be impaired by time restraints, NPs may opt to address the most common parental concerns regarding immunizations in a handout format such as a flyer or informational pamphlet.

Education suggesting various coping techniques for parents who are disturbed by their child's pain/crying/anxiety may prove to be beneficial in the long run as they will be more likely to return for the next set of immunizations if empowered with the tools to cope with their child's resistance to immunizations. Parents should be educated on how to help relieve their child's immunization anxiety prior to arriving at the clinic. In addition, parents should be given information on how to react to their child's immunization anxiety while in the clinic.

\section{Future Research}

Additional research could identify the reasons why parents exempt their children from receiving any immunizations and compare these reasons with why parents hesitate in immunizing their children. If both exempting and hesitant parents have similar concerns, perhaps interventional programming can address each of these concerns simultaneously and, therefore, better utilize interventional funding. Also, by comparing perceptions of exempting and hesitant parents, perhaps it can be identified at what point a hesitant parent transitions to being an exempting parent, which would help program planners carefully design intervention strategies.

Because the child's pain/crying/ anxiety is recognized as a common reason why parents hesitate in immunizing their children, it may be helpful to identify ways to reduce a parent's concern in this regard. Topical anesthetics have been studied; however, at this time, the routine use of these agents in clinical practice is not endorsed (Schechter, 2007). Most topical anesthetic 
agents are not practical for use prior to administering immunizations because of a delayed onset of action ranging from 10 minutes to 1 hour. While vapo-coolant sprays are inexpensive and anesthetize the skin in approximately 30 seconds, study results are conflicting regarding their effectiveness prior to immunizations (Schechter). Perhaps future research could further investigate the use of vapo-coolant sprays prior to immunizations. If the use of a local anesthetic spray successfully reduces the child's pain, it also may reduce the child's anxiety and crying during future immunizations, thus encouraging parents to return for the next immunization in a more timely manner.

\section{Limitations of Study}

The participants compose a convenience sampling that may not represent the entire population. Additionally, we did not include children younger than 6 months of age in this study because each child needed to be at least 6 months overdue for their next immunization. Another limitation of this study is that the sample is different than the national population; thus the findings cannot be generalized to many other populations.

\section{CONCLUSION}

It is imperative for NPs to understand that parents who hesitate in having their children immunized have differing demographic backgrounds that need to be assessed before developing interventions to increase immunization rates among this target population. $\mathrm{Pa}-$ rental confusion on when to return for a child's next set of immunizations is a common reason for hesitating from having children immunized on time. Instituting an immunization reminder program may help parents return for subsequent immunizations in a timely manner. Parents continue to express concerns regarding vaccine safety, despite the fact that most report receiving the majority of their immunization information from their health care provider. Finally, many parents are concerned about their child's pain/crying/anxiety when receiving immunizations and may benefit from educational programming focused on coping techniques.

\section{STATEMENT OF CONFLICT OF INTEREST}

We would like to acknowledge the National Association of Pediatric Nurse Practitioners and Wyeth Pharmaceuticals, the Brigham Young University Nursing Research and Scholarship Council, the American Academy of Nurse Practitioners Foundation and AstraZeneca Pharmaceuticals, and the Nurse Practitioner Healthcare Foundation and Sanofi Pasteur Pharmaceuticals for funding this research.

\section{REFERENCES}

Bundt, T., \& Hu, H. M. (2002). National examination of the relationship between compliance predictors and the immunization status of children. Abstract for the Academy of Health Services Health Policy Meeting, 19, 795-803.

Cassidy, K., Graham, J. R., McGrath, P. J., Finley, G. A., Smith, D. J., Morley, C., et al. (2002). Watch needle, watch TV: Audiovisual distraction in preschool immunization. Pain Medicine, 3, 108-118.

Cochran, C. E., Smith, D. R., Reid, T., Morrow, H., \& Ramirez, J. (2003). Protecting Texas children: Evidence-based recommendations for improving childhood vaccination rates. Texas Medicine, 99, 52-60.

Green, C., \& Lee, P. (2006, March). Immunization exemption: Taking it personal. Why do Utah parents claim personal exemptions. Lecture presented at the 40th National Immunization Conference; Atlanta, GA. Retrieved January 25, 2008, from http://coc.confex.com/cdc/ nic2006/techprogram/P10238.HTM

Gust, D., Strine, T., Maurice, E., Smith, P., Yusuf, H., Wilkinson, M., et al. (2004). Underimmunization among children: Effects of vaccine safety concerns on immunization status. Pediatrics, 114, 16-23.

Kim, S. S., Frimpong, J. A., Rivers, P. A., \& Kronenfeld, J. J. (2007). Effects of ma- ternal and provider characteristics on up-to-date immunization status of children aged 19-35 months. American Journal of Public Health, 97, 259-266.

Kimmel, S. R., Burns, I. T., Wolfe, R. M., \& Zimmerman, R. K. (2007). Addressing immunization barriers, benefits, and risks. Journal of Family Practice, 56, S61-S69.

Luman, E. T., Barker, L. E., McCauley, M. M., \& Drews-Botsch, C. (2005). Timeliness of childhood immunizations: A state-specific analysis. American Journal of Public Health, 95, 13671374.

Luman, E. T., Barker, L. E., Shaw, K. M., McCauley, M. M., Buehler, J. W., \& Pickering, L. K. (2005). Timeliness of childhood vaccinations in the United States: Days undervaccinated and number of vaccines delayed. Journal of the American Medical Association, 293, 1204-1211.

Luman, E. T., McCauley, M. M., Stokley, S., Chu, S. Y., \& Pickering, L. K. (2002). Timeliness of childhood immunizations. Pediatrics, 110, 935-939.

Niederhauser, V. P., \& Markowitz, M. (2007). Barriers to immunizations: Multiethnic parents of under- and unimmunized children speak. Journal of the American Academy of Nurse Practitioners, 19, 15-23.

Schechter, N. L., Zempsky, W. T., Cohen, L. L., McGrath, P. J., McMurtry, C. M., \& Bright, N. S. (2007). Pain reduction during pediatric immunizations: Evidence-based review and recommendations. Pediatrics, 119, e1184-e1198.

Shui, I. M., Weintraub, E. S., \& Gust, D. A. (2006). Parents concerned about vaccine safety: Differences in race/ethnicity and attitudes. American Journal of Preventive Medicine, 31, 244-251.

Simmons, T., \& O'Neill, G. (2001). Households and families: 2000. Census 2000 brief. Retrieved April 10, 2008, from http://www.census.gov.

Smith, P. J., Chu, S. Y., \& Barker, L. E. (2004). Children who have received no vaccines: Who are they and where do they live? Pediatrics, 114, 187-195.

United States Census Bureau. (2000a). Profile of general demographic characteristics for Utah: 2000. Retrieved January 25, 2008, from http://factfinder.census.gov.

United States Census Bureau. (2000b). State \& country quickfacts. Retrieved January 25,2008 , from http://quickfacts. census.gov/qfd/states/00000.html

Utah Department of Health. (2006). Utah selected as national kick-off state for infant immunization week; 2006. Retrieved January 25, 2008, from http:// health.utah.gov/pio/nr/2006/041806-In fantlmmNR.pdf 